\title{
Comparison of Strategic Leadership: Steve Jobs and Tim Cook
}

\author{
Hyeonjoo Kim \\ Correspondence: Hyeonjoo Kim, Coventry University, UK. E-mail: degree1682@gmail.com \\ Received: August 11, 2020 \\ doi:10.11114/bms.v6i3.5010 \\ Accepted: September 4, 2020 \\ Online Published: September 10, 2020 \\ URL: https://doi.org/10.11114/bms.v6i3.5010
}

\begin{abstract}
Research for leadership of CEO constructs understanding of effective way of improving organizational performance crucially. Behavior of employees as unconditionally following their leaders would be significant example of leader's effective influence to employees. Factors of leadership may include cultural, environmental, individual and some other perspectives which benefit both employees and organizations. Valued Apple Inc.'s organizational performance would be focused in terms of leadership from CEOs.
\end{abstract}

Keywords: transformational leadership, transactional leadership, leadership competencies, cultural dimension

\section{Introduction}

Five key elements of leadership are consisting of influence, organizational objectives, leader-followers, change and people. Influencing can be organizational relationship between leaders and followers. Followers as employees can perform and change organizational innovation under motivation which influenced by leader. Thus, leadership is significant management skill (Lussier \& Achua, 2010).

\begin{tabular}{cll}
\hline & KEY FACTS & \multicolumn{1}{c}{$\begin{array}{c}\text { MAJOR PRODUCT AND } \\
\text { SERVICES }\end{array}$} \\
\hline Address & Applie Inc., 1 Infinte Loop, Cupertino, & MacBook \\
& California, 95014, USA & Mac Pro \\
Website & http://www.apple.com & iMac \\
Telephone & 14089961010 & iPod \\
Fax & 14089742113 & iTunes \\
Employees & 32,000 & iPhone \\
Turnover (\$m) & $32,479.0$ & Apple TV \\
Financial Year end & September & Displays \\
NASDAQ National & APPL & Operating system software e.g. Mac \\
Market Ticket & & OS X Application software e.g. Life \\
& & Final cut Internet software e.g. \\
\end{tabular}

Figure 1. Apple Inc

Apple Inc. is well known in public and one of most innovative IT advanced company. Its headquarter is located in Cupertino, California, USA. As well as not only large sized IT companies such as Google Inc. and HP, but also plenty of IT startup companies are located around the region. Main products and services of Apple are desk-top and laptop computer, smart pad, smart phone, Apple TV and so on (DATAMONITOR, 2009).

Brand value of Apple has tremendous impact in the market place and it has won award of Interbrand ranking $39^{\text {th }}$ place in 2006 and $24^{\text {th }}$ in 2008. The value in dollar reaches $\$ 13,724$ million in 2008. It is well known to the public that Apple performs for significant process and investment on research and development. One of product, iPhone achieved one of fastest growing in the market place and it had been constantly growing in the third quarter in 2008 . The sales by comparison in 2007 was increased by 11.5\% (MarketWatch, 2009). 


\section{Research Issue and Proposal}

Apple Inc. was founded by Steve Jobs and Steve Wozniak in January 1977. This company eventually became one of remarkable IT devices producer. However, there was failure of launching product which caused resignation of Steve Jobs in 1985. Later, Steve Jobs established a company named NeXT and it was successful. However, Apple was on the crisis and staggering when Steve Jobs was back to serve as CEO of Apple in 1997. That was turning point for Apple and later it had increased its brand value with tremendous market share. Within significant outcome of great achievement in IT industry, Leadership of Steve Jobs can be considerably key element of organizational management (MarketLine, 2012).

\section{Cultural Dimension}

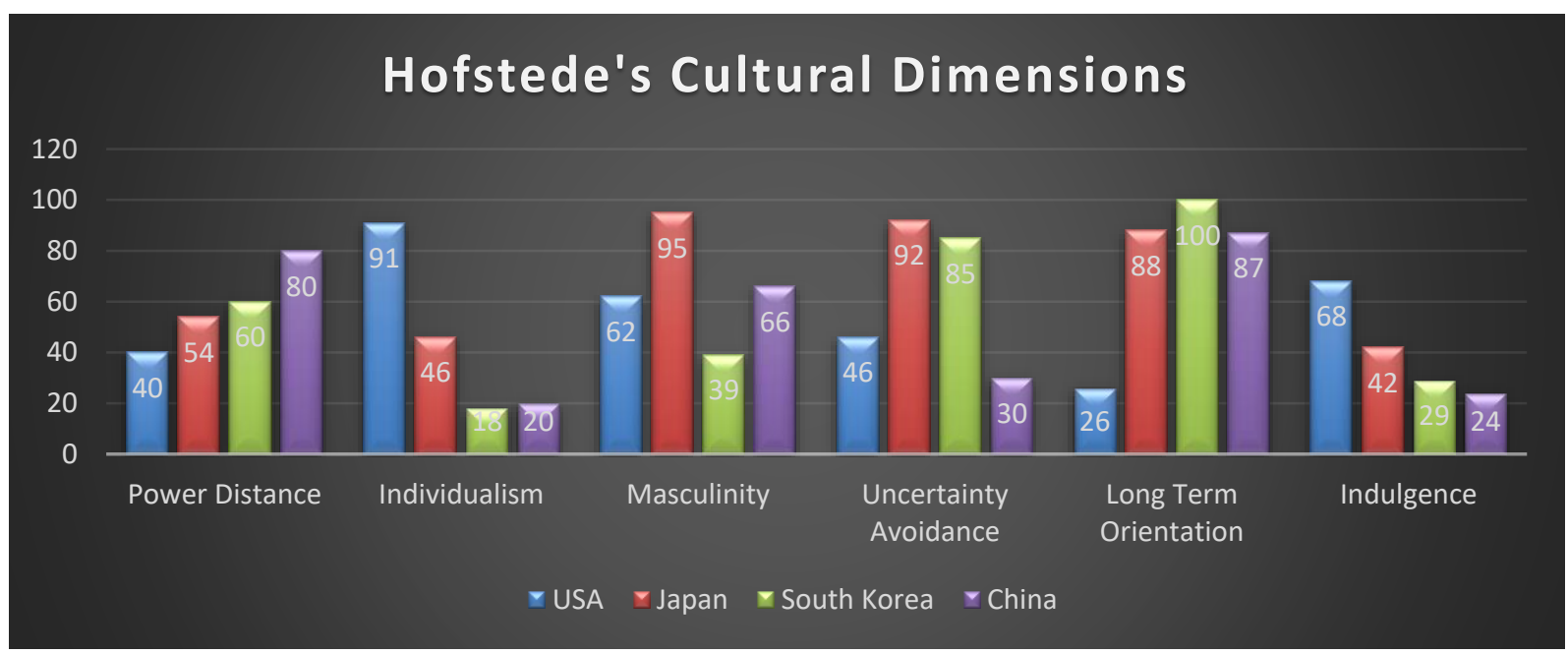

Figure 2. Dimensions Graph for 4 countries (KIM, 2020)

Apple's main suppliers are Far East Asia based companies. Japanese and Korean producers are suppliers of hardware technology and Chinese and Taiwanese companies facilitated assembly lines of products (Apple, 2017).

It is considerably expected that leadership of Apple may influence significantly on its suppliers. Among other cultural involvement, harmoniously cooperating would be considerable for smooth business relationship and operation. Culture in the United States indicates that people are more likely to have individualism and indulgence, but have short power distance and long-term orientation (Hofstede, 2017).

WWDC (Worldwide Developers Conference) is host show that is presentation of CEO and other executives of Apple to developers which can be inferred as there is not much gap of power distance in the company. It is somewhat different aspect from Far Eastern culture which CEO usually veiled from public attention. Both of CEO, Steve Jobs and Tim Cook show up at WWDE and lead this event with presentation. Apple's top management culture is highly active and having clear interact with employees and developers (WWDC, 2017).

Individualism in US is higher than that of Far East. By analyzing Apple's products, product management and orientation are toward to personal usage devices such as laptop, smartphone and smart pad. The products are inferred that the firm focused on developing products based on American individualism (MarketLine, 2017).

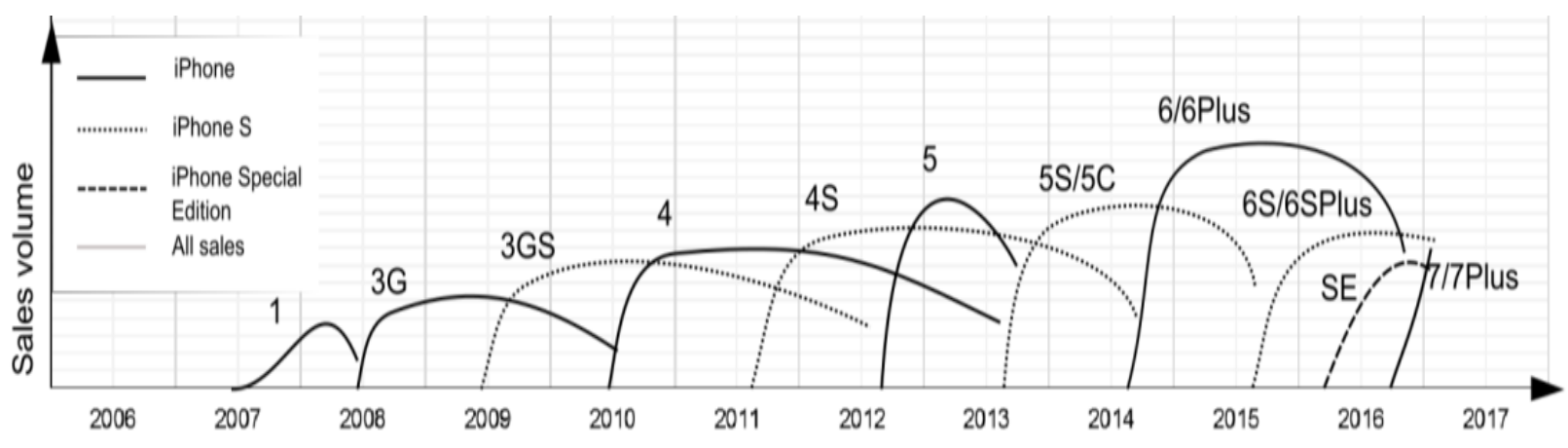

Figure 3. The life cycle of all the iPhone models (Więcek-Janka, et al., 2017) 


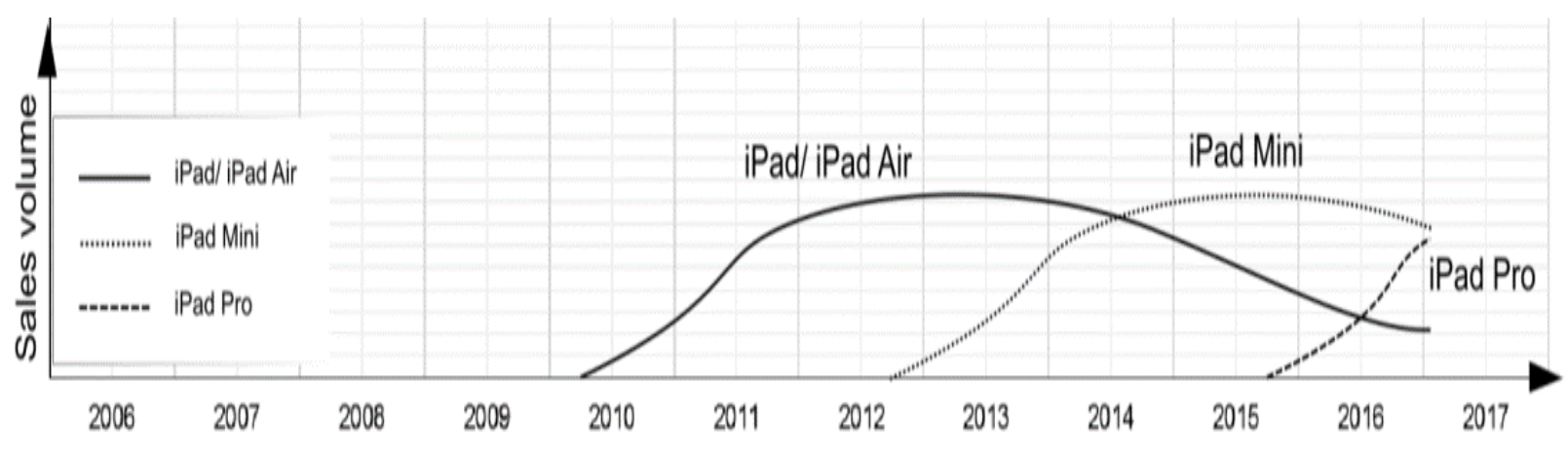

Figure 4. The life cycle of the iPad lines (Więcek-Janka, et al., 2017)

The life cycle of Apple's iPhone clearly states that the company's product renews annually. As well as other products renewal cycle does not reach more than a decade. Apple release new upgraded products regularly and previous products can be outdated. This might be inferred as management of Apple urges and operates as not long-term orientated. Apple's work place is not likely providing for permanent job and employees are at risk of layoff at any time. There is always in and out in Apple's working environment. By analysis of the life cycle of products, this environment is within short-term orientation (Więcek-Janka, et al., 2017)

The products of Apple are showing off high price by comparison to that of competitors. There are many smart phone brands and iPhone shows one of the highest price. The price can be regarded as the products of Apple are fancy items or luxurious brand. High proportion of iPhone sales reached in US market, however population of USA is not the highest in the world. Life style and consumption pattern for indulgence of cultural perspectives are inferred as that American culture typically is more incline to indulgence than that of China, that of Japan and that of Korea (Więcek-Janka, et al., 2017).

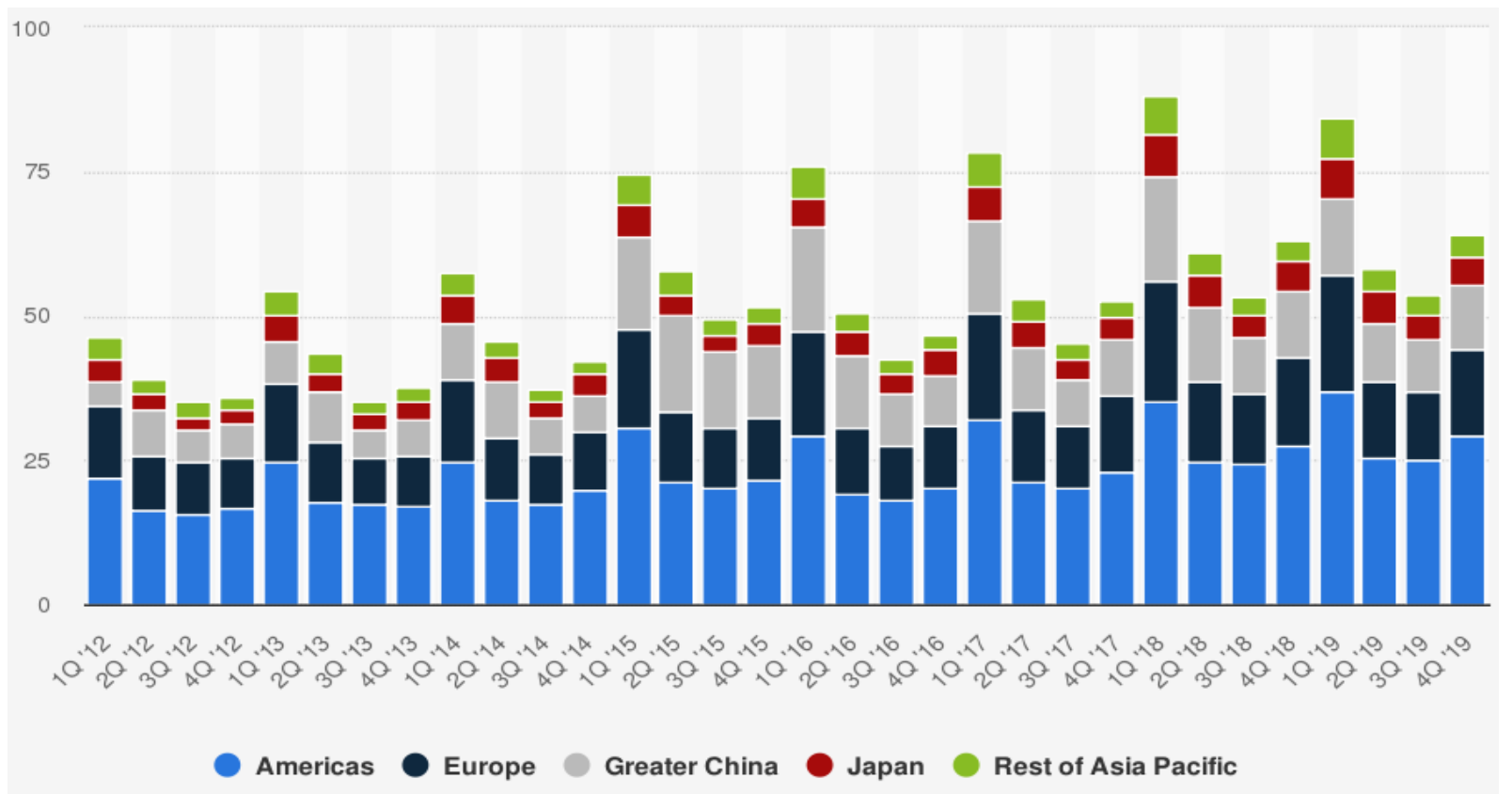

Figure 5. Revenue of Apple by country/region from 2012 to 2019 (in billion US \$)

The figure above highlights the products of Apple took most demand from Americas (Statista, 2019).

By analysis of the life cycle of the Apple, organizational environment focused on products and prices of cultural indulgence in USA are how Apple management leads and dominates in US market effectively (Więcek-Janka, et al., 2017). 


\section{COACHING SURVEY}

$1 \quad 66 \%$ of CEO feels lonely and do not take any message from outside

2 All CEOs wants to be coached

3 Even $60 \%$ of CEO answers that they want progress to be secret, others share, and scholars advise for keeping it transparent to be the board helps to foster bonds and ameliorate relationship with the board, confidentiality is not the answer as coaching is losing stigma

Most concerned for CEO is how to handle conflict in ranks

5 The boards want CEOs to improve talent development by more coaching, leading and delegation for the firms which offers strengthen organization and successful performance

CEOs hire coaching service for internal and external improvement

Figure 6. Maria Presenting - Universal Leadership Approaches \& Cultural Dimensions

CEOs of Apple, Steve Jobs and Tim Cook maybe different to this survey. By analysis of cultural dimension, top management of Apple is actively interconnected with employees and developers of the company. Leadership of this company's CEO is very unique in style and typical American leadership style (Hofstede, 2017).

\section{Transformational Leadership and Transactional Leadership}

Transformational leadership serves to adjust the system by simplifying to employees the issues in the present system and a compelling vision of what a new structure of the organizations should be. Transactional leadership pursues to hold down stable statue in the organization though social and economics trades and organizational performances (Biering, 2017).

\subsection{Steve Jobs}

Assembly line factories of Apple are operating in China and many employees are exploited. Wage gap between American and Chinese shows significantly wide gap. Working condition in China is not comparable to that of developed countries and long and harsh work load had led 18 of production line employees attempted suicide and at least had died among them in Foxconn's Longhua factory. Issue of the production line of Apple highlights that leadership of top management had been transactional leadership for producing line control. Not providing stable work place indicates that it is opposite to transformational. It is usually not common to find following vision of organization in production line (Worstall, 2016).

However, situation at home is different to that of manufacturing site in China. CEO of Apple, Steve Jobs was hero by introducing iPhone and praised by not only customers, but also its employees. Returning from NeXT as CEO, Steve Jobs focused on only four computers to overcome potential disadvantage. He urged to simplify for all products and cut clutters. CEO, Steve Jobs thought the best way to demonstrate simplicity is integration of all of hardware, software and other device which he pursued for integration. According to Steve Jobs, people are very busy and they have other things to do rather than thinking about how to integrate their computer and devices. So, his statement affects Apple Inc. and this needed to take responsibility end to end. According to statement of Steve Jobs, my passion is building reliable firm which delivers motivation to produce great products and everything else is secondary. The reason for company is to earn high profit that is motivation. Thus, money is the main motivation. And the people we hire, who gets promoted what you discuss in meeting. This is referred as transactional leadership but as he intended it and wanted to put best products before profit. Steve Jobs wanted employees not to be a slave to focus groups but make products that ourselves want. While he was designing iPhone, he had decided Gorilla glass for iPhone but they did not have capacity yet. He subdued and put all engineers and scientists to solve the problem and it worked and made. By a consequence, every glass on iPhones and iPads is with Gorilla glass. He bended reality and leaded organization to better position (Isaacson, 2012).

As above mentioned, only thing to transactional leadership shows was to motivate with firm's profit which is directly meaning of employees benefit but rest of them are more transformational leadership. Steve Jobs had big picture and a scrupulous detail in his mind. He was both of an engineer and a designer. He had great passion and creative idea on the best products. He had never waited for customer's needs as tried to figure out what they are going to want before they do. He was not great inventor but had mastermind in putting all things together. And he did not slow down on process. These are Steve Jobs' unique characteristic which is significantly highlight how his personality could lead Apple with transformational leadership (Bengtson, 2012).

Steve Jobs was a perfectionist and had pushing for perfection. Survey as above shows that many CEOs are loners and away from outside advises but Steve Jobs was not. He had pursued face-to-face meeting. Most significant 
transformational leadership he showed is combining the humanities with the sciences. There are great technologies, creative design and artists but no one could not put all together. The real leadership of Steve Jobs had tremendously impulse on Apple's performance and innovation (Isaacson, 2012).

Leadership of Steve Job is both of transactional leadership and transformational leadership. He motivated for firm profit and discussion for profit and promotion. However, mainly his leadership is based on transformational leadership. There are 5 main factors for his leadership Focus, Simplify, Take responsibility end to end, Put products before profits and Tolerate only "A" players (Isaacson, 2014).

\subsection{Tim Cook}

CEO, Steve Jobs had resigned his position from Apple Inc. on 24 ${ }^{\text {th }}$ of August, 2011 and he passed away on 5th of October, 2011. The board of Apple had decided Tim Cook as new CEO of the firm. There was one big issue that Apple stock price was dropped by $5 \%$ after announcement of resignation of CEO Steve Jobs. His medical leave caused firm's share price dropping by $6 \%$ in 2011. Losing Steve Jobs impacted major issue for Apple Inc. with not only share price, but also company's leadership. Tim Cook administration has been started with risk of both of internal and external issue by losing of Steve Jobs (MarketLine, 2012).

Present Apple's new leadership is Chief Executive Officer, Tim Cook and he also serves its Board of Directors. He achieved a Bachelor of Science in Industrial Engineering from Auburn University in Alabama and an MBA from Duke University's Fuqua school of Business. His previous experiences are vice president of Corporate Materials of Compaq. Earlier to his experience at Compaq, he was the chief operating officer for Intelligent Electronics. He has 12 years working experience in IBM. Responsibilities of his leadership at Apple takes global sales and operations, supply chain, sales and service (Cook, 2017).

Apple's second shocking situation during Tim Cook era is security and terror issues related to Federal Government following by tragic incident in San Bernardino, California in December 2015 (Drew, 2016).

A gunman was killed while conflicting with police and his act of crime identified as terrorism. After this incident, there was argument between Apple and US Federal Government. Unlocking dead suspect's iPhone was asked from Federal authority. This was one big challenge for Apple. As one of big IT corporation and with ethical concerned on protection of personal privacy, the firm denied unlocking the iPhone (Perry, 2016).

Request from Federal Bureau of Investigation (FBI) made publishing not simple denial but it was illustration of how Tim Cook's transformational leadership reaches and impacted from outside and the result of influence at Apple. Tim Cook's reply was as “... carry so much personal information on our phones today, and there are new data breaches every week affecting individuals, companies, and governments ... if we lose control of our data, we put both our privacy and our safety at risk" (Perry, 2016).

The legal challenge for Apple and FBI cut major attention. There was unprecedented competition and tension. FBI tried to unlock but Apple had to protect privacy for Apple product users. In order with innovation to adapt to survive in the situation, Apple needed of developing more on its OS and encryption (Perry, 2016).

This protection is related cultural aspect and individualism in the United States is highest by comparison and to provide better service with this cultural aspect, Apple was supposed to protect unlocking and upgrade of OS and device (Hofstede, 2017).

Tim Cook's transformational leadership kept and will keep its products protected from accessing personal device to collect data. Apple and FBI legal issue was ended on $29^{\text {th }}$ of March, 2016. Federal Magistrate Judge, Sheri Pym cancelled order to Apple assisting FBI for unlocking the iPhone. Tim Cook has well defensed from sudden risk from political level of issue and demonstrated well developed transformational leadership (Perry, 2016).

\section{Key Elements of Leadership Competencies}

The Top 10 Leadership competencies, Grouped Into Five Themes

When 195 global leaders were asked to rate 74 qualities, these rose to the top (KIM, 2020). 


\begin{tabular}{|l|r|c|l|}
\hline \multicolumn{4}{|c|}{ PERSENTAGE OF RESPONDENTS } \\
\hline $\mathbf{1}$ & Strong ethics \& safety & $67 \%$ & Has high ethical and moral standards \\
\hline $\mathbf{2}$ & Self-organizing & 59 & Provides goals and objective with loose guidelines/direction \\
\hline $\mathbf{3}$ & & 56 & Clearly communicates expectations \\
\hline $\mathbf{4}$ & Efficient learning & 52 & Has the flexibility to change opinions \\
\hline $\mathbf{5}$ & Nurtures growth & 43 & Is committed to my ongoing training \\
\hline $\mathbf{6}$ & Connection \& belonging & 42 & Communicates often and openly \\
\hline $\mathbf{7}$ & & 39 & Is open new ideas and approaches \\
\hline $\mathbf{8}$ & & 38 & Creates a feeling of succeeding and failing together \\
\hline $\mathbf{9}$ & & 38 & Helps me grow into a next-generation leader \\
\hline $\mathbf{1 0}$ & & 37 & Provides safety for trial and error \\
\hline
\end{tabular}

Figure 7. Top 10 leadership competencies (Giles, 2016)

\subsection{Has High Ethical and Moral Standards}

As above mentioned, Tim Cook's leadership on how to deal with personal privacy on protection delivers great example for high ethical and moral standards. Tim Cook's transformational leadership significantly focused on this factor during Apple vs. FBI privacy confliction era. How to lead its organization for morally standardized and ethically correct goal is not easy to pursue. As a CEO of Apple, Tim Cook had faced with political power which is one of US Federal government official. His achievement to deal with it would be highly applauded (Perry, 2016).

However, Steve Jobs' oversea management had failed due to employees' suicides with low income, high work load, and other negative factors. Steve Jobs' transactional leadership did not affect firm performance overall and this morally un-acceptable incidents could impact on organization to wrong pass way in short and long-term performance (Worstall, 2016).

Thus, CEO Tim Cook has higher ethical and better moral standards than those of Steve Jobs and this factor can influence the organization with positive influence on employees.

\subsection{Provides Goals and Objectives with Loose Guidelines/Direction}

Steve Jobs' product management could illustrate clear objects and specific goal in his leadership. Apple products were significantly innovated during the Steve Jobs Administration. Releasing software iTunes impacted on sales of iPod and it was innovated as iPhone eventually. From the first attempt, the firm demonstrated its product strategy to have employed for the integration direction and the model with both the highest costs and highest risk. As Steve Jobs' expectation was produce 'the perfect machine', it provides goals objectives with loose quidelines/direction. Steve Jobs indeed is tremendously creative at product innovation (Hawn, 2004).

\subsection{Cleary Communicates Expectations}

Cultural dimension as above shows that there is less power distance in the United States (Hofstede, 2017). By watching WWDC, there is always CEO's presentation for products introduction and it is from both Steve Jobs and Tim Cook. Communication between leaders and employees is supposed to be very clear (WWDC, 2017).

\subsection{Has the Flexibility to Change Opinions}

Steve Jobs, himself is significantly a stubborn CEO. His intention for building products was only rule for employees and all had to follow his vision. Tim Cook also shows that he is not too flexible when Apple's crisis came on with iPhone unlocking order from Federal authorities. Both Steve Jobs and Tim Cook is not easy to be bended and pursuing their own superintend with strong and stubborn leadership (Perry, 2016).

Steve Jobs was the classic narcissistic leader (Yu, 2013).

\subsection{Is Committed to My Ongoing Training}

Steve Jobs attended at Reed College in Portland Oregon which is one of the most prestigious schools but he dropped out of school. However, Tim Cook earned MBA degree which can be interpreted as he was training himself for better management and leadership for the firm where he works for (Cook, 2017).

Education is not only training for further career, but this shows a clear evidence for training himself for the firm by long-term perspective. 


\subsection{Communicates often and Openly}

Steve Jobs indeed work with employees to develop creative products and it could be proper example for communicates often and openly. Steve Jobs' wishes for products development and command are now all openly searchable through online search. However, Tim Cook only shows his communication at WWDC (Isaacson, 2012).

\subsection{Is Open to New Ideas and Approaches}

While Steve Jobs' leadership, all creative new products were introduced to the market. Not only software, but also hardware is created during his administration. Such as iTunes, iPod, iPhone, iPad and MacBook air were sensational issue (Finkle \& Mallin, 2010).
iPhone $X$
iPhone 8 Plus
iPhone 8
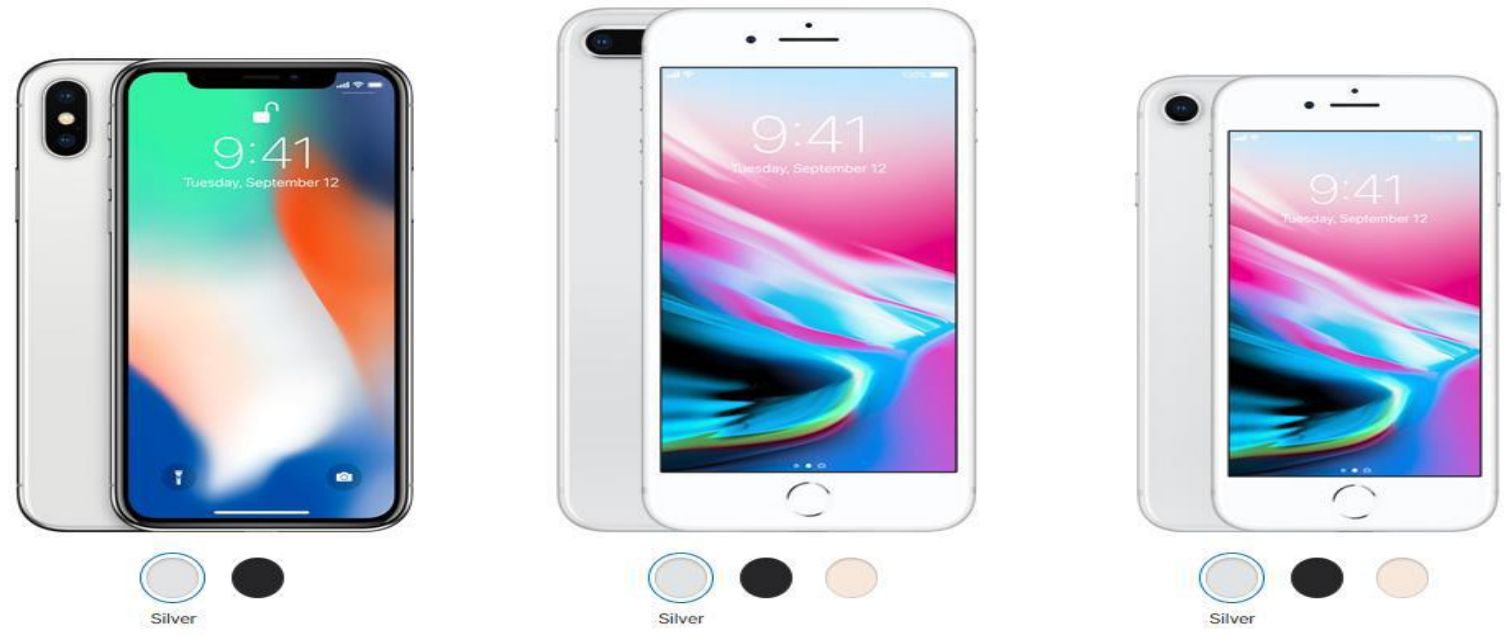

Figure 8. iPhones Segmentation (Apple, 2017)

Meanwhile in Tim Cook's regime, there is no new creative products introduced yet. But every year, existing products are getting upgraded with hardware point of view (WWDC, 2017).

\subsection{Creates a Feeling of Succeeding and Falling Together}

Leadership of Steve Jobs shows that he motivated employees with profit and money which can be creates a feeling of succeeding together. Leader and followers could share success by earn profit (Bengtson, 2012).

Both Steve Jobs and Tim Cook leads presentation with other managers at WWDC which is they go project successfully together (WWDC, 2017).

\subsection{Helps Me Grow Into a Next-Generation Leader}

Steve Jobs left Apple by illness leave and death and Tim Cook has taken the leadership. Steve Jobs left Apple and had experience on other company what he founded and came back for leadership at Apple. Experience outside of Apple helps Steve Jobs' leadership (MarketLine, 2012).

Tim Cook has leadership training from Duke University's MBA. His academic and experience in other firms helped himself growing into a next-generation leader (Cook, 2017).

\subsection{Provides Safety for Trial and Error}

Tim Cook had protected personal data when Apple faced legal challenge against US government. His stubborn leadership to protect individualism and personal data was well affected Apple and it had very positive perspective for both firm's value and performance (Perry, 2016).

\section{How Leadership Competencies Can Be Developed}

\subsection{Learn}

Academic training for leadership can tremendously develop CEO's ability to lead the organization. Tim Cook had attended MBA class at Duke. MBA class usually supports, trains and teaches leadership which Tim Cook learned from the school. One of economics theory, learning effect (learning curve) could demonstrate how and why learning is 
effective way to improve performance (Kagan, 2017).

\subsection{Motivation}

Steve Jobs motivated his employee for firm's profit. Steve Jobs left Apple and came back when Apple had deeply going under performance. Situation at the time was as bad as great recession. Minuet problem or mistake could fail firm's fortune. Every employees were supposed to work hard and participate every section that is possible (MarketLine, 2017).

Motivation for work at Apple was tremendously crucial point at the time of return of Steve Jobs. Steve Jobs' transactional leadership encouraged employees with profit and money. As well as Apple's crisis time seems to be his motivation to save dying company. Motivation can improve leadership and work ability.

\subsection{Understanding Cultural Difference}

Steve Jobs' failure of transactional leadership in manufacturing process in China was caused by negligence, overlooking and misunderstanding of other culture which could be prevented by careful management. Apple is an American company and it is also global company who leads many of Far Eastern companies. Understanding of other culture could bring about one of great leadership competency (Worstall, 2016).

\section{Conclusion}

Comparison of leadership of Steve Jobs and Tim Cook in same organization that is Apple Inc. brought about understanding and how leadership is effective and why it should be well developed for not only short- term perspective, but also long-term perspective.

Leadership is lonely progress for most of CEOs, but Apple's CEOs were very actively acted and performed best leadership for its organization which made Apple one of the greatest companies and most innovated firms in the world. Nevertheless, Steve Jobs failed leadership in China, he had been leading the firm successfully with both transactional and transformational leadership.

Steve Jobs had Charisma leadership. He was powerful on products innovation and creation and had power to perform and lead Apple to right direction. His charisma leadership came from motivation to save plunging Apple to lead top of its industry.

Tim Cook follows Steve Jobs' legacy impeccably. His leadership is transformational leadership and he does not force to create different approach or process to idea as Steve Jobs' 'think differently', but all products are going under innovation process with His leadership. Stubborn ethical leadership made Apple's strong OS upgrade by Apple vs FBI tension.

Both Steve Jobs and Tim Cook show one of most impressive leadership. Steve Jobs had passion to harness firm to improve with creative mind. His passion at work place could attract with employees to follow well on the track of work pass way. He set the road to go further. Nowadays, Tim Cook is on the road to lead Apple. His leadership well going on the track of Steve Jobs made. Tim Cook's leadership is more transformational and on the stable mind.

There is no way who is better on leadership aspect. These two leaders have own personalities on their leadership. Two different leaderships are suitable with process of specific time for its innovation of both company and products. Time of innovation had arrived for Apple, so Tim Cook is suitable CEO for current Apple Inc., and leadership he has is more respected.

\section{Reference}

Apple. (2017). Apple Website introducing iPhones, s.l.: Apple Inc.

Apple. (2017). Supplier List, s.l.: Apple Inc..

Bengtson, T. (2012). Inside Jobs. North Western Financial Review, 1(6), 4.

Biering, J. (2017). Stragtegic Leadership Seminar and Lecture, s.l.: IBA.dk.

Cook, T. (2016). Apple Leadership, s.l.: https://www.apple.com/leadership/tim-cook/.

Cook, T. (2017). Apple Leadership, s.l.: https://www.apple.com/leadership/tim-cook/.

DATAMONITOR. (2009). Apple Inc. Company Profile. DATAMONITOR, 16(3), 1-12.

Drew, R. (2016). Apple's Tim Cook fights order to share San Bernardino shooter's iPhone info. syracuse.com, 17(2).

Finkle, T. A., \& Mallin, M. L. (2010). STEVE JOBS AND APPLE, INC.. Journal of the International Academy for Case Studies, 16(7), 31-40.

Giles, S. (2016). The Most Important Leadership Competencies, According to Leaders Around the World. Havard Business Review, 15(3). 
Hawn, C. (2004). If He's So Smart...Steve Jobs, Apple, and the Limits. FastCompany, January, pp. 68.

Hofstede. (2017). Cultural Dimension, s.1. Retrieved from https://www.hofstede-insights.com/

Isaacson, W. (2012). The Real Leadership Lessons of Steve Jobs. Harvard Business Review, April, 93-102.

Isaacson, W. (2014). Steve Jobs' leadership secrets. Executive Leadership - Business Management Daily, November, 3.

Kagan , J. (2017). Learning Curve, s.1.: Investopedia.

KIM, H. (2020). Analysis of How Tesla Creates Core Innovation Capability. International Journal of Business and Management, 15(6), 42-61. https://doi.org/10.5539/ijbm.v15n6p42

Lussier, R. N., \& Achua, C. F. (2010). LEADERSHIP Theory, Application, \& Skill Development. s.1.:South-Western Cengage Learning.

MarketLine, (2012). Apple Inc. The Steve Jobs Effect - MarketLine Case Study, s.1.: MarketLine.

MarketLine, (2017). Apple, s.1.: MarketLine.

MarketLine. (2012). Apple Inc., s.l.: MarketLine.

MarketWatch. (2009). Company Spotlight: Apple Inc., s.1.: Datamonitor.

Perry, S. (2016). Tim Cook, a Case Study on the Effects of. s.1., The SANS Institute.

Richtel, M., \& Chen, B. X. (2014). Tim Cook, Making Apple His Own. 15(6), 1-8.

Statista. (2019). Revenue of Apple by geographical region from the first quarter of 2012 to the 4th quarter of 2019. Retrieved from https:/www.statista.com/statistics/382175/quarterly-revenue-of-apple-by-geograhical-region/:Statista.com

Więcek-Janka, E., Papierz, M., Kornecka, M., \& Nitka, M. (2017). Apple Products: A Discussion of the Product Life Cycle, s.1.: Atlantis Press.

Worstall, T. (2016). The Guardian Wrong - Apple, Suicide, China, Wages - About, s.1.: Retrieved from https:/www.forbes.com/sites/timworstall/2016/09/20/the-guardian-wrong-apple-suicide-china-wages-about-everyt hing-all-the-time/\#14d48f202e93

WWDC. (2017). Worldwide Developers Conference 2017. Retrieved from https://developer.apple.com/wwdc17/: Apple Inc.

Yu, H. H. (2013). Decoding Leadership. Journal of Business \& Management, 19(1), 33-44.

\section{Copyrights}

Copyright for this article is retained by the author(s), with first publication rights granted to the journal.

This is an open-access article distributed under the terms and conditions of the Creative Commons Attribution license which permits unrestricted use, distribution, and reproduction in any medium, provided the original work is properly cited. 